\title{
Assessing Barriers to Therapeutic Regimens for Young People with Juvenile Idiopathic Arthritis
}

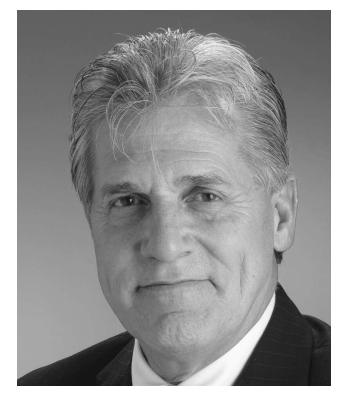

The Health Belief Model (HBM) has been one of the most widely used theories in health behavior research over the past 5 decades $^{1,2}$. Originally developed in the early 1950 s to understand why people failed to take advantage of preventive health services (such as hypertension screening), the HBM was later extended to adherence to prescribed medical regimens ${ }^{3,4}$.

The HBM posits 5 major sets of variables that predict or explain adherence: (1) perceived susceptibility (including the person's perceived risk of contracting or re-contracting a condition or acceptance of an existing condition); (2) perceived severity (the person's evaluation of the medical and social consequences of contracting an illness or not receiving treatment); (3) perceived benefits (the person's judgment of the perceived benefits of taking a particular health action); (4) perceived barriers (the person's perception of impediments to adhere to recommended treatments, including a cost-benefit analysis where the person weighs the pros and cons of taking action); and (5) cues to action (internal cues, such as disease symptoms, or external cues, such as prompting by others, that trigger action). In addition, later formulations of the HBM have included Bandura's concept of self-efficacy ${ }^{2}$.

Two comprehensive reviews found substantial empirical support for the HBM and concluded that perceived barriers were the most powerful predictors of a wide range of health practices including adherence to medical regimens $\mathrm{s}^{3,5}$. Because of their predictive power, researchers have been developing measures of barriers to adherence. Measures have been developed to assess barriers to pediatric chronic disease regimens, including those for young people with asthma ${ }^{6}$, cystic fibrosis $^{6}$, epilepsy ${ }^{7}$, human immunodeficiency virus ${ }^{8}$, obstructive sleep apnea ${ }^{9}$, organ transplants ${ }^{10}$, and sickle cell disease $^{11}$. In the aggregate, these measures have identified similar barriers as reported by patients and caregivers, such as forgetting to carry out the regimen, communication problems with healthcare providers, and psychosocial adjustment problems. Once information has been obtained about barriers to adherence unique to a particular patient and family, researchers and clinicians can design interventions to overcome these specific barriers. Patients and caregivers can be engaged in problem-solving to identify potential ways to reduce barriers. For example, if a patient forgets to take medication doses, prompting strategies could be recommended such as setting a watch alarm or using a phone app to prompt taking of medications.

Although measures have been developed to assess barriers to many different chronic pediatric conditions, no studies to my knowledge have developed a measure to assess barriers to medical regimens for patients with juvenile idiopathic arthritis (JIA), until the publication of the Favier, et al study reported in this issue of The Journal ${ }^{12}$. Favier and colleagues collected data from 578 parents and 99 patients across 7 pediatric rheumatology clinics in the United States. They assessed barriers across 4 treatment modalities including adherence to oral medications, injectable medications, infusions, and physical/occupational therapy recommendations. They found that the most common barriers were worry about the future consequences of therapy, pain, forgetting, side effects, and embarrassment related to the therapy.

There are several strengths of this study. First, the development of the barrier items was done by a multidisciplinary group including rheumatologists, nurse practitioners, and psychologists. They also involved patients with JIA and their caregivers. Second, they have a relatively large sample size as a result of recruitment across 7 sites. Third, they assessed barriers to 4 treatment modalities, whereas most barrier measures focus on 1 modality such as oral or inhaled medications. In spite of these strengths, I and the other reviewers identified a major flaw in the study that almost precluded me from recommending the manuscript for publication. That flaw was that a measure of adherence was not included in the study, so we cannot know the relationship between

See Barriers to adherence in JIA, page 690

Personal non-commercial use only. The Journal of Rheumatology Copyright @ 2018 . All rights reserved. 
barriers and adherence. There are at least feasible patient and/or parent self-report measures that could have been used $^{13}$. However, the measure was unique and comprehensive and should be out in the literature for use by other researchers (the authors indicated that the measure can be obtained by contacting them).

Identifying barriers is an important first step in developing and validating adherence interventions that are tailored to the unique challenges families face in trying to adhere to regimens for $\mathrm{JIA}^{13}$.

MICHAEL A. RAPOFF, $\mathrm{PhD}, \mathrm{ABPP}$, Ralph L. Smith Professor of Pediatrics, University of Kansas Medical Center, Department of Pediatrics, Kansas City, Kansas, USA.

Address correspondence to Dr. M.A. Rapoff, 3901 Rainbow Blvd., Kansas City, Kansas 66103-7330, USA. E-mail: mrapoff@kumc.edu

Photo courtesy of J. Belmont.

\section{REFERENCES}

1. Clark NM, Houle CR. Theoretical models and strategies for improving disease management by patients. In: Shumaker SA, Ockene JK, Riekert KA, editors. The handbook of health behavior change. 3rd ed. New York: Springer; 2009:19-37.

2. Strecher VJ, Rosenstock IM. The Health Belief Model. In: Glanz K, Lewis FM, Rimer BK, editors. Health behavior and health education: theory, research, and practice. 2nd ed. San Francisco: Jossey-Bass; 1997:41-59.

3. Janz NK, Becker MH. The health belief model: A decade later. Health Edu Q 1984;11:1-47.
4. Rosenstock IM. Historical origins of the health belief model. Health Educ Monogr 1974;2:328-35.

5. Becker MH. The health belief model and personal health behavior. San Francisco: Society for Public Health Education; 1974.

6. Modi AC, Quittner AL. Barriers to treatment adherence for children with cystic fibrosis and asthma: What gets in the way? J Pediatr Psychol 2006;31:846-58.

7. Modi AC. Monahan S, Daniels D, Glauser TA. Development and validation of the Pediatric Epilepsy Medication Self-Management Questionnaire. Epilepsy Behav 2010;18:94-9.

8. Buchanan AL. Montepiedra G, Sirois PA, Kammerer B, Garvie PA, Storm DS, Nichols SL. Barriers to medication adherence in HIV-infected children and youth based on self- and caregiver report. Pediatrics 2012;129:e1244-51.

9. Simon SL, Duncan CL, Janicke DM, Wagner MH. Barriers to treatment of paediatric obstructive sleep apnoea: Development of the adherence barriers to continuous positive airway pressure (CPAP) questionnaire. Sleep Med 2012;13:172-7.

10. Simons LE, Blount RL. Identifying barriers to medication adherence in adolescent transplant recipients. J Pediatr Psychol 2007; 32:831-44.

11. Modi AC, Crosby LE, Guilfoyle SM, Lemanek KL, Witherspoon D, Mitchell MJ. Barriers to treatment adherence for pediatric patients with sickle cell disease and their families. Child Health Care 2009;38:107-22.

12. Favier L, Taylor J, Loiselle Rich K, Jones K, Vora S, Harris J, et al. Barriers to adherence in juvenile idiopathic arthritis: a multicenter collaborative experience and preliminary results. J Rheumatol 2018;45:690-6.

13. Rapoff MA. Adherence to pediatric medical regimens. 2nd ed. New York: Springer; 2010

J Rheumatol 2018;45:588-9; doi:10.3899/jrheum.171399 